\title{
Temporal and Spatial Trends of Spring Maize Irrigation Water Requirement in Northeast China in Recent 60 Years
}

\author{
Zongyue Ren, Xiaojing Liu \\ College of Tourism and Geographic Science, Jilin Normal University \\ Siping 136000, Jilin \\ Zorinrzy@163.com

\section{东北地区近 60 年春玉米灌溉需水量时空变化趋 势分析} \\ 任宗悦, 刘晓静 \\ 吉林师范大学旅游与地理科学学院 \\ 四平 136000 , 吉林 \\ Zorinrzy@163.com
}

\begin{abstract}
In this paper, the daily meteorological data of 78 stations in Northeast China from 1958 to 2017 were used to calculate the evapotranspiration and water requirement during the growth period of spring maize. Combined with M-K trend test and GIS spatial analysis technology, the spatial and temporal trends of irrigation water demand during the growth period of spring maize in the northeastern region were analyzed, and the water demand of spring maize growth period in Northeast China was discussed to provide a theoretical basis for ensuring food production in the main maize producing areas. The results show: in terms of time, the average annual irrigation water requirement during the whole growth period ranges from -237.7 to $346.9 \mathrm{~mm}$, and $92 \%$ of the sites irrigation water requirement in the study area is greater than 0 . In the milky ripening to maturation stage, the water requirement for irrigation is high and the situation is increasing. From sowing to emergence period, $96 \%$ of the sites have a downward trend. In space, there is a significant regional difference in the distribution of irrigation water equirement, and the overall situation is basically reduced from east to west. With the growth of spring maize, the water shortage in western Jilin, northwestern Liaoning and western Heilongjiang has also increased.
\end{abstract}

Keywords-Northeast China, spring maize, irrigation water requirement, Penman-Monteith formula, crop coefficient method

摘要一本文采用东北地区 78 个站点 1958-2017 年的逐日气 象数据, 计算春玉米生育期内的蒸散量和需水量, 并结合 MK 趋势检验和 GIS 空间分析技术，分析了整个东北地区近 60a 春玉米生育期内灌溉需水量的时空变化趋势, 探讨东北地区

基金项目: 吉林师范大学研究生科研创新计划资助项目（研 创新 201945)

作者简介：任宗悦（1995-），女，硕士研究生。研究方向： 自然灾害监测、风险评估与管理。Email: Zorinrzy@163.com 通讯作者：刘晓静（1985-），女，博士，主要从事自然灾害 风险评价与管理方面的教学和科研工作。Email: liuxj@jlnu.edu.cn
春玉米生长期的需水情况, 为保障玉米主产区的粮食生产提 供理论基础。结果表明: 时间上, 全生育期内年均灌溉需水 量变化范围在-237.7 346.9mm, 研究区内 92\%的站点灌溉需 水量大于 $\mathbf{0}$, 乳熟一成熟阶段灌溉需水量偏高且情况不断加 剧, 播种一出苗阶段研究区内 $96 \%$ 的站点都呈下降趋势。空 间上, 灌溉需水量分布存在着明显的地区差异, 全局基本呈 现由东向西先减少后增加的规律。随着春玉米的生长, 吉林 西部、辽西北和黑龙江西部的缺水情况也不断加重。

关键词一东北地区, 春玉米, 灌溉需水量, Penman-Monteith 公式, 作物系数法

\section{I. 引言}

近年来，农业气象灾害频繁多发，有“黄金玉米 带”之称的东北地区属于旱灾频发的区域。仅 2017 年, 黑龙江、吉林、辽宁省的总作物受灾面积约有 348.3 万 公顷, 其中旱灾受灾面积达到了 225 万公顷, 占总受灾 面积的 $64.6 \%$ 。对东北地区春玉米生育期内灌溉需水量 时空分布特征进行研究, 可以合理分配灌溉资源, 减少 灾损，为区域农业旱灾防御提供理论依据。

当前, 对灌溉需水量的研究可以分为三种, 第一种 基于 Penman-Monteith 公式和作物系数法计算区域作物 水分的供需情况 [1-3], 第二种则是利用统计函数建立作 物需水量与降雨和潜在蒸散的定量关系 [4-6], 第三种则 是通过田间试验来研究玉米的需水规律 [7]。而作物系数 主要受土壤、气候、作物生长状况和管理方式等诸多因 素影响 [8], 故各地作物系数具有一定差异, 不能一概而 论。前两种在计算区域灌溉需水量时均采用统一的作物 系数, 第三种方法虽然通过田间试验获得的作物系数较 为准确, 但是无法实现区域作物灌溉需水量的研究。因 此, 本文对研究区按照作物生长系数特征进行分区, 对 东北地区近 60 年春玉米各生育期内灌溉需水量的时空变 化趋势进行分析, 旨在为东北地区玉米种植区的农业灌 排和防灾减灾提供理论依据。 


\section{II. 资料与方法}

\section{A. 研究区概况}

东北地区是中国玉米主产区之一，包括黑龙江省、 吉林省、辽宁省及内蒙东部的通辽市和赤峰市, 大部分 区域年降水量在 500 800mm, 雨热同期。整个东北农作 区耕地面积约占全国耕地面积的 $15 \%$, 是我国主要的商 品粮种植基地。依据春玉米生长特征, 对研究区进行分 区，如图 1 所示。

\section{$B$. 数据来源与处理}

1) 气象数据: 本文选取了东北玉米产区内 78 个气象 台站 1958-2017 年的逐日气象数据，数据资料均来自国 家气象信息中心（https://data.cma.cn/）的中国地面气候 资料日值数据集（V3.0）, 并对个别缺测值和突变值进 行插补和剔除等处理。

2) 玉米生长系数: 国际粮农组织（FAO）建议玉米生 育期划分为初始生长期、发育期、生育中期和生育后 期。结合东北地区春玉米的品种和生长特点, 根据文献 [9-10]和田间数据, 确定了东北地区春玉米各生育阶段 的起止时间（表 1)。参考 FAO 计算的和前人修订的玉 米作物系数 $[8,11]$, 结合北方春玉米干旱等级标准 [12], 确定了研究区各地区的春玉米作物系数值（表 2）。

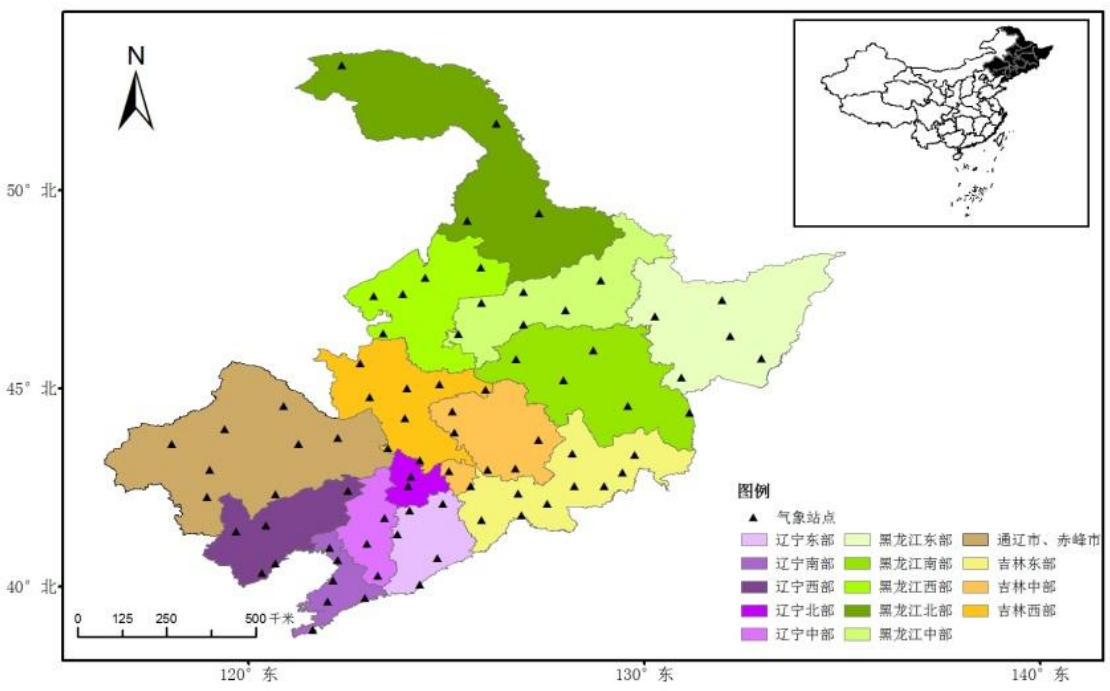

图 1.研究区概况及气象站点分布图

Figure 1. Overview of the study area and distribution of meteorological sites

表 1 东北地区玉米各生育阶段起止时间

Table 1 Starting and ending time of each growth stage of maize in Northeast China

\begin{tabular}{ccc}
\hline $\mathrm{FAO}$ 建议的 4个生育阶段 & 生育阶段 & 起止时间 \\
\hline 初始生长期 & 播种一出苗 & 4 月下旬至 5月中旬 \\
发育期 & 出苗一拔节 & 5 月下旬至 6月中旬 \\
生育中期 & 拔节一抽穗 & 月下旬至 7 月中旬 \\
生育后期 & 抽穗一乳熟 & 7 月下旬至 8 月中旬 \\
\hline
\end{tabular}

表 2 东北地区春玉米各月作物系数值

Table2 Monthly crop coefficient of spring maize in Northeast China

\begin{tabular}{|c|c|c|c|c|c|c|c|}
\hline 省 & 地区 & 4 月 & 5 月 & 6 月月 & 7 月 & 8 月 & 9 月 \\
\hline \multirow[t]{5}{*}{ 黑龙江省 } & 东部 & 0.30 & 0.49 & 0.75 & 1.08 & 1.02 & 0.74 \\
\hline & 南部 & 0.30 & 0.48 & 0.71 & 1.04 & 1.11 & 0.80 \\
\hline & 西部 & 0.30 & 0.37 & 0.69 & 1.11 & 1.01 & 0.65 \\
\hline & 北部 & 0.30 & 0.49 & 0.77 & 1.03 & 1.02 & 0.74 \\
\hline & 中部 & 0.30 & 0.45 & 0.76 & 1.10 & 1.02 & 0.74 \\
\hline \multirow[t]{3}{*}{ 吉林省 } & 西部干旱区 & 0.30 & 0.40 & 0.80 & 1.26 & 1.25 & 0.73 \\
\hline & 中部平原区 & 0.30 & 0.45 & 0.63 & 1.15 & 0.96 & 0.74 \\
\hline & 东部山区 & 0.30 & 0.40 & 0.70 & 1.10 & 0.95 & 0.70 \\
\hline \multirow[t]{5}{*}{ 辽宁省 } & 东部 & 0.47 & 0.68 & 0.92 & 1.13 & 1.12 & 0.84 \\
\hline & 南部 & 0.46 & 0.70 & 0.92 & 1.21 & 1.11 & 0.83 \\
\hline & 西部 & 0.36 & 0.51 & 0.72 & 1.12 & 1.04 & 0.77 \\
\hline & 北部 & 0.39 & 0.50 & 0.70 & 1.17 & 1.12 & 0.86 \\
\hline & 中部 & 0.40 & 0.52 & 0.76 & 1.21 & 1.13 & 0.89 \\
\hline 内蒙古自治区 & 通辽市、赤峰市 & 0.45 & 0.51 & 0.71 & 1.11 & 1.04 & 0.77 \\
\hline
\end{tabular}




\section{C. 研究方法}

1) 春玉米生育期内灌溉需水量的计算: 作物灌溉需水 量主要由作物需水量及有效降雨量两个要素共同决定。 当区域外部来水量大于玉米需水量时, 则认为该区域不 需要灌溉; 当区域外部环境无法为玉米提供充足的需水 量时, 则此时玉米的缺水量即为区域需灌溉的水量 [13]。因此, 玉米在某一生育阶段的灌溉需水量应为:

$$
I R_{i}=E T_{c i}-P_{e i}
$$

式中: $E T_{c i}$ 为 $i$ 生育阶段内作物需水量, $\mathrm{mm} ; P_{e i}$ 为 $i$ 生育阶段内作物逐日有效降雨量的总和, $\mathrm{mm}$ 。 $I R_{i}$ 为作 物这一生育阶段内的灌溉需水量, $\mathrm{mm}$ 。 $P_{e i}$ 采用降雨有 效利用系数法[13]进行计算, $E T_{c i}$ 采用 $\mathrm{FAO}$ 推荐的 Penman-Monteith 公式[14]和作物系数法计算[15]。

2) Mann-Kendall 检验法: Mann-Kendall 检验法是由 Mann 和 Kendall 提出并发展起来的一种非参数统计方 法, 不要求样本遵从一定的分布, 且检验结果基本不受 少数异常值的干扰。当 $\mathrm{M}-\mathrm{K}$ 统计变量 $\mathrm{Z}$ 值大于 0 时, 表示时间序列数据随着时间的推移呈增加趋势, 小于 0 时表示呈减少趋势, 且 $\mathrm{Z}$ 的绝对值超过 1.64 或 2.32 时，分别对应趋势检验的显著性水平为 0.05 、 $0.01[16]$ 。 M-K 趋势检验已被世界气象组织推荐并已广 泛应用于降水、径流、气温和水质等的分析研究 [17]。

\section{III. 结果与分析}

\section{A. 东北地区春玉米不同生育阶段灌溉需水量时间变化 趋势}

对各站点 1958-2017 年东北春玉米各生育期的灌溉 需水量进行 $M-K$ 趋势检验, 得到 $M-K$ 统计量 $Z$ 值, 并 进行空间插值后得出了研究区灌溉需水量的时间变化趋 势分布图, 如图 2 所示。

全生育期内, 研究区内东北部呈下降趋势, 西南地 区则呈上升趋势。黑龙江省中部的两个站点的 $M-K$ 统计 量 Z 值均超过了显著性 $\alpha=0.01$ 时的临界值-2.32, 表明 灌溉需水量呈显著下降趋势。播种一出苗阶段, 研究区
96\%的站点都呈下降趋势, 黑龙江东南部、吉林中部、 辽宁东北部和中部下降趋势都十分显著。出苗一拔节阶 段, 除吉林东部和辽宁东南部的站点呈上升趋势外, 研 究区 $79 \%$ 的站点呈下降趋势, 其中北部地区显著下降, 并超过了 $99 \%$ 的置信水平。拔节一抽穗阶段, 研究区北 部和西南部的灌溉需水量增加, 其余地区下降, 但变化 趋势不明显。抽穗一乳熟阶段, $55 \%$ 的站点灌溉需水量 呈上升趋势, $42 \%$ 的站点灌溉需水量呈不显著下降趋 势。乳熟一成熟阶段, 研究区内大部分地区的 $M-K$ 统计 量 Z 值大于 0 , 其中 14 个站点的灌溉需水量呈显著上升 趋势, 并超过了 $95 \%$ 的置信水平, 这是由于近年来气候 变化, 极端天气增加, 春玉米生长季温度增高加快 [18], 导致了需水量上升。

\section{B. 东北地区春玉米全生育期灌溉需水量空间分布特征}

灌溉需水量的大小与当地纬度地区的气候条件有着 直接关系, 计算 1958-2017 年研究区内各站点的 60 年年 均灌溉需水量, 并进行反距离插值后得到春玉米各生育 期灌溉需水量空间分布图（图 3)。

由图 3a 可知, 整个东北地区的灌溉需水量存在着明 显的地区差异, 灌溉需水量最大的区域是内蒙地区, 其 次是黑龙江西部、吉林西部、辽宁西北部。全生育期 60 年平均灌溉需水量变化范围在-237.7 346.9mm 之间, 研 究区内呈现由东向西先减少后增加的规律。

由图 3b-f 可知, 随着春玉米的生长, 各地区灌溉需 水量的差异也在不断增大。灌溉需水量小于 0 的地区从 吉林东部逐渐向研究区北部蔓延, 一直到乳熟一成熟阶 段, 整个辽宁东部、吉林东部和黑龙江中部的灌溉需水 量均为负值。而研究区内干旱情况也随着春玉米的生长 不断加重, 出苗一拔节期和乳熟一成熟期灌溉需水量大 于 $40 \mathrm{~mm}$ 的区域, 分别较前一生育期增加了 $141.8 \%$ 和 $32.0 \%$ 。乳熟一成熟阶段灌溉需水量大于 $60 \mathrm{~mm}$ 的区域 占整个研究区面积的 $15 \%$, 主要集中在内蒙地区, 表明 60 年来内蒙地区玉米在该生育阶段频繁遭遇干旱。

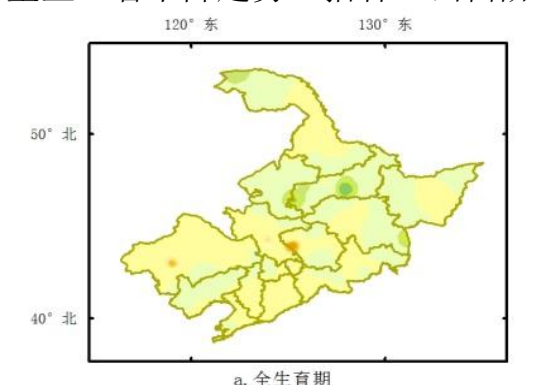

a. 全生育期

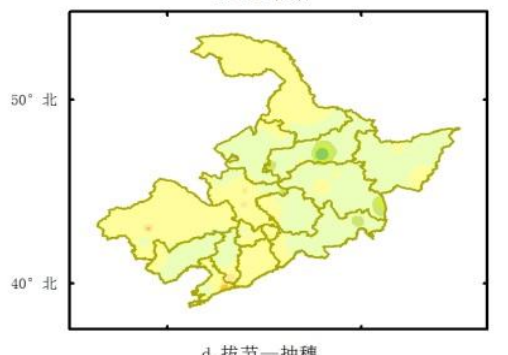

M-K检验统计量Z值

$\square$ 显著下降 (99\%置信水平) $\square$ 显著下降 (90\%置信水平) $\square$ 显著下降 (95\%置信水平) $\square$ 不显著下降 $130^{\circ}$ 东

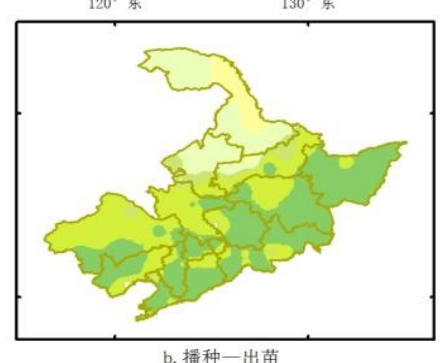

b. 播种一出苗

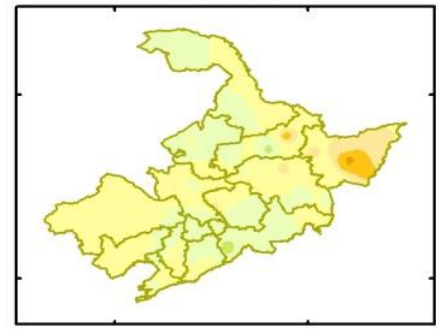

e. 抽穗一乳熟

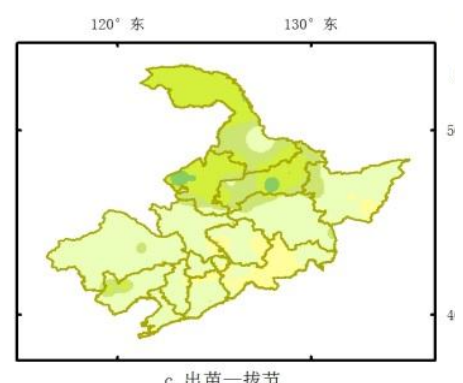

c. 出苗一拔节

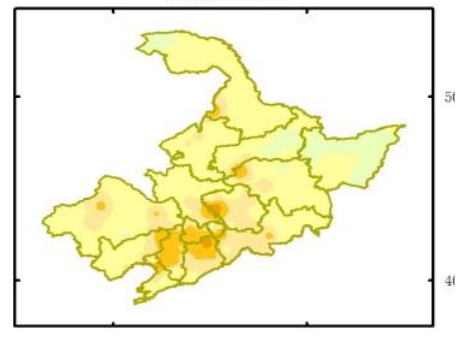

f. 乳欮一成养

$\square$ 显著上升 (90\%置信水平) $\square$ 显著上升 (99\%置信水平)

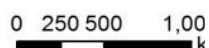

图 2. 近 60 年内各生育期灌溉需水量变化趋势空间分布图

Figure 2. Trend of irrigation water demand during each growth period in the past 60 years 


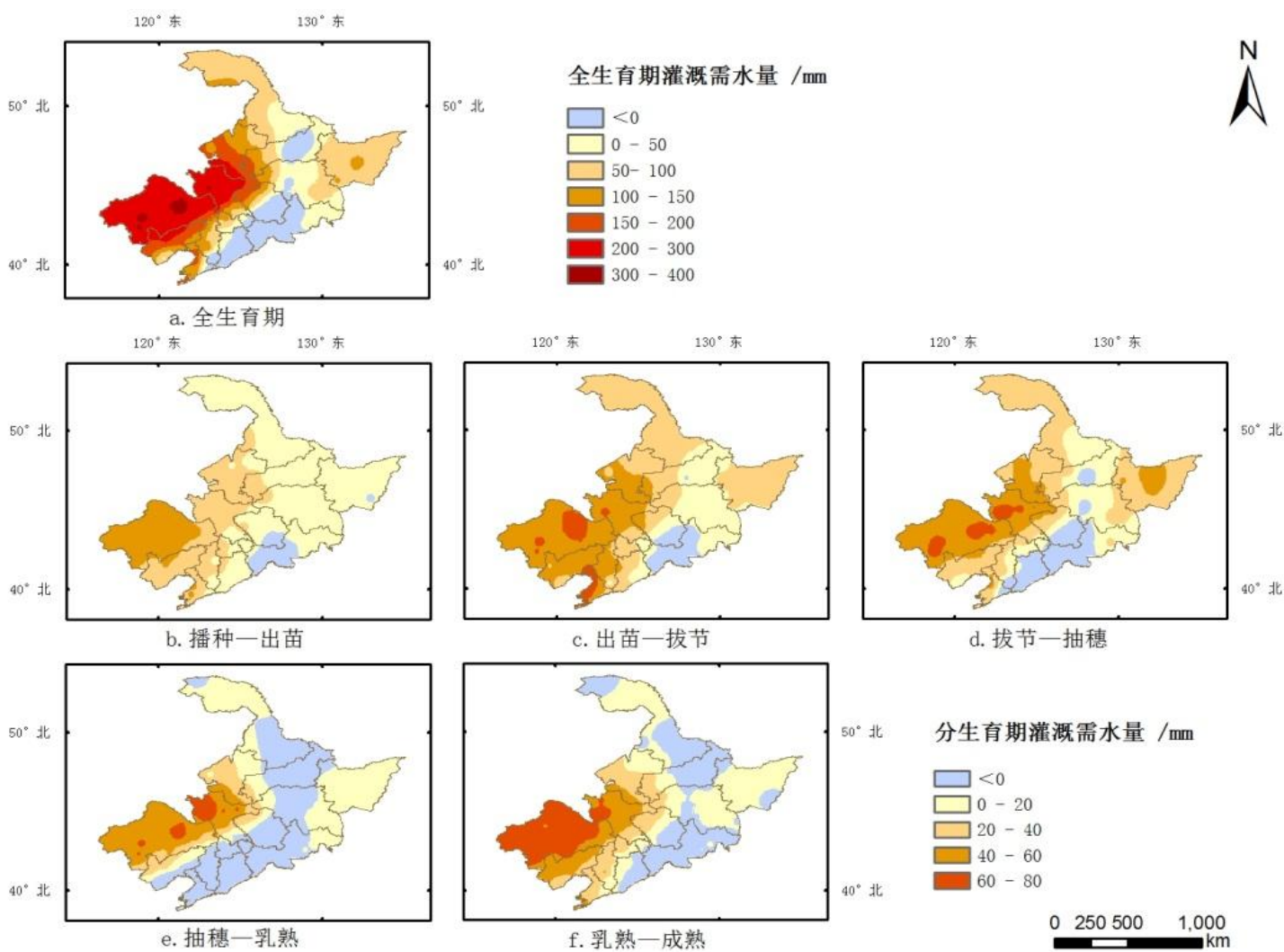

图 3.各生育期内灌溉需水量空间分布图

Figure 3. Spatial distribution of irrigation water demand during each growth period

IV. 结论与讨论

在全球气候变暖的大背景下, 春玉米生育期内发 生旱灾的频率也在不断升高，因此对灌溉需水量进行 时空变化趋势的分析, 能够为区域农业干旱灾害的防 御提供理论依据。本文以东北地区为例, 分析了春玉 米全生育期不同生育阶段灌溉需水量的时空变化特 征, 结果如下:

（1）全生育期内, 研究区内灌溉需水量呈东北地 区下降，西南地区上升趋势。播种一出苗阶段 $96 \%$ 的 站点都呈下降趋势。出苗一拔节阶段, 北部地区显著 下降，并超过了 $99 \%$ 的置信水平。乳熟一成熟阶段， 研究区内大部分地区需水情况不断加剧。

（2）全生育期 1958-2017 年平均灌溉需水量变化 范围在-237.7mm 346.9mm 之间, 存在着明显的地区 差异, 全局呈现由东向西先减少后增加的规律。随着 春玉米的生长, 吉林西部、辽西北和黑龙江西部的缺 水情况也不断加重。出苗一拔节期, 研究区内灌溉需 水量大于 $40 \mathrm{~mm}$ 的区域较前一生育期增加了 $141.8 \%$ 。 乳熟一成熟阶段灌溉需水量大于 $60 \mathrm{~mm}$ 的地区主要集 中在内蒙地区。

本文在计算时没有考虑前期降水在土壤中的渗透 和保留, 所以存在一定误差, 在下一步工作中将充分 考虑前期水分遗留和区域干旱程度, 以期进一步完善 该研究。
参考文献

[1] 聂堂哲,张忠学,林彦宇,陈鹏,孙仲益.1959-2015 年黑龙江省玉 米需水量时空分布特征.农业机械学报,2018,49(07):217-227.

[2] 高晓容,王春乙,张继权,薛绪掌.近 50 年东北玉米生育阶段需水 量及旱涝时空变化.农业工程学报,2012,28(12):101-109.

[3] 刘钜,汪林,倪广恒,从振涛.中国主要作物灌溉需水量空间分布特 征.农业工程学报,2009,25(12):6-12.

[4] 黄仲冬,齐学斌,樊向阳,李中阳,梁志杰.气候变化对河南省冬小 麦和夏玉米灌溉需水量的影响.灌溉排水学报,2015,34(04):10-13.

[5] 南纪琴,肖俊夫,刘战东,刘祖贵,秦安振. 不同水文年型北方春玉 米需水量时空变化特征研究.灌溉排水学报,2014,33(Z1):45-49.

[6] 张建平,王春乙,杨晓光,赵艳霞,刘志娟,王靖,陈艳英.未来气候变 化对中国东北三省玉米需水量的影响预测.农业工程学 报,2009,25(07):50-55.

[7] 王颖辉,汤鹏程,李曙光,田雨春,李嘉琪.内蒙古东部干旱年份玉 米需水规律及灌溉制度优化. 干旱地区农业研 究,2018,36(01):108-114.

[8] 张淑杰,周广胜,李荣平. 基于浴度相关的春玉米逐日作物系数及 蒸散模拟.应用气象学报,2015,26(06):695-704.

[9] 穆佳,赵俊芳, 郭建平. 近 30 年东北春玉米发育期对气候变化的 响应.应用气象学报,2014,25(06):680-689.

[10] 刘晓静,马东来,张继权,陈鹏. 辽西北地区玉米干旱的识别方法. 干旱区研究,2018,35(03):722-727.

[11] 陈素华,王志春,李丹.内蒙古通辽市、赤峰市春玉米水分亏缺评 价及区域差异。内蒙古农业大学学报(自然科学 版),2016,37(04):20-25.

[12] 中国气象局. 北方春玉米干旱等级. 北京: 中国气象出版社, 2015. China Meteorological Administration.The Drought Grades for Maize in North.Beijing: China Meteorological Press,2015.

[13] Xiaojing Liu,Donglai Ma,Jiquan Zhang,Peng Chen. The Study of Estimation on Maize Irrigation Water Requirement in the northwest of Liaoning Province. The Journal of Risk Analysis and Crisis Response,2019, Vol.9-1:52-59 
[14] Allen R G, Pereira L S, Raes D, et al. Crop Evapotranspiration : Guidelines for Computing Crop Water Requirments. Rome : FAO, 1998

[15] 高超,李学文,孙艳伟,周婷,罗纲,陈财.淮河流域夏玉米生育阶段 需水量及农业干旱时空特征.作物学报,2019,45(02):297-309.

[16] 魏凤英. 现代气候统计诊断与预测技术 (第 2 版). 北京: 气象出 版社, 2007

[17] Kisi O, Ay M. Comparison of Mann-Kendall and innovative trend method for water quality parameters of the Kizilirmak River,Turkey . Journal of Hydrology, 2014, 513: 362-375.

[18] 陈长青, 类成霞, 王春春, 张卫建. 气候变暖下东北地区春玉米生产 潜力变化分析.地理科学,2011,31(10):1272-1279 